\title{
Mobile phones and wrong numbers: how Maasai agro-pastoralists form and use accidental social ties in East Africa
}

\author{
$\underline{\text { Timothy D. Baird }}^{1}, \underline{\text { J. Terrence McCabe }}^{2,3}$ Emily Woodhouse $^{4}, \underline{\text { Isaya Rumas }}^{5}$, Stephen Sankeni ${ }^{5}$ and Gabriel Ole Saitoti $^{5}$
}

\begin{abstract}
Mobile phones are recognized as important new tools for rural development in the Global South, but few studies have examined how phones can shape social networks. This study documents a new type of social tie, enabled by mobile phones, that to our knowledge has not previously been discussed in academic literature. In 2018, we discovered that Maasai pastoralists in northern Tanzania create new social ties through wrong numbers, a phenomenon with implications for theory on social networks and path dependency. We used a mixed ethnographic and survey-based design to examine the following: (1) the conditions under which wrong number connections (WNCs) are made; (2) the incidence of these connections in the study area; and (3) the association between WNCs and multiple livelihood strategies. Working in 10 rural communities in Tanzania, we conducted 16 group interviews with men about their phone use and found that WNCs are diverse and can provide households with important information, resources, and opportunities from an expansive geographic area. (Nine separate interviews with groups of women revealed that women do not create WNCs.) Based on early qualitative findings, we designed and conducted a standardized survey with 317 household heads. We found that $46 \%$ of respondents have had WNCs. Furthermore, multivariate regression models show a significant association between WNCs and the controversial practice of leasing land in one district. Taken together, our findings show that WNCs can be seen as innovations in social networking that reduce path dependency, increase the range of potential outcomes, and hold important implications for rural livelihoods in East Africa.
\end{abstract}

Key Words: East Africa; Maasai; mobile phones; pastoralism; path dependency; social networks; social ties

\section{INTRODUCTION}

Mobile phones are recognized as important new tools for rural development in the Global South, but evidence of their potential to boost agricultural yields, improve market efficiencies, and save lives has been mixed (Aker and Ksoll 2016, Wyche and Steinfield 2016, Haenssgen and Ariana 2017, Marler 2018, Quandt et al. 2020). And phone use is mushrooming. In sub-Saharan Africa, mobile subscriptions per 100 people have increased sharply from fewer than 2 in 2010 to more than 82 in 2018 (ITU 2020). Amidst this growth, the idea that mobile phones can be transformative remains evident. Across the world, phones affect how people realize and express their identities, inhabit their social networks, and conduct their work (Ling 2008, Duncombe 2018, Kivikuru 2019). Few studies, however, have examined how phones can shape social ties.

Here we document a new type of social tie that, to our knowledge, has not previously been discussed in academic literature and has implications for theory on social networks and rural livelihoods. During our fieldwork in Maasai communities in northern Tanzania in 2018, we discovered that Maasai men create new social ties through wrong numbers. This process begins when an individual simply mis-keys a phone number and places a call, as would happen anywhere in the world. When the call is answered, and the parties discover the error, one of two things can happen: (1) the individuals end the call; or (2) they begin to chat. This paper is about what happens when Maasai begin to chat.

\section{Social ties, technology, and livelihoods}

The Strength of Weak Ties by Mark Granovetter (1973) is one of the most cited papers in science. It describes how individuals are more likely to find employment through friends of friends, or "weak ties," than through their "strong ties" with close family and friends. This idea has served as a center of gravity around which scholarship on social networks and diffusion has orbited for decades. Since Granovetter's paper, the internet and mobile technologies have transformed the ways in which social networks are created, maintained, and evolve (Horst and Miller 2006, Ling 2008, Castells et al. 2009).

Notably, researchers' efforts to examine social, economic, and environmental change in the Global South have been greatly outpaced by the rapid adoption of phones in the past decade, their ubiquity even in rural areas, and the steady evolution in how they are used (Duncombe 2014, 2018). Of the relatively few studies of the consequences of phone use, most have understandably focused on information exchange and market integration (Muto and Yamano 2009, Aker 2011, Tadesse and Bahiigwa 2015). Few studies have focused on the social outcomes of phone adoption, and how these undergird livelihoods and land use.

Cultural anthropologists and human geographers often focus on group-level social structures and processes, e.g., social relations, to better understand the social consequences of economic and technological events and trends. This approach is well suited to characterizing broad efforts and themes at scale, but important factors can also be found in idiosyncratic behaviors at the level of individuals, an area under-theorized in research on human/ environment interactions in the Global South. Notably, very little research has examined the effect of mobile phones on social network tie formation, i.e., the connection between two people; a dyad, which could be instructive in fields like anthropology and geography given their longstanding interests in cooperation (Henrich 2006, Apicella et al. 2012, Kasper and Mulder 2015,

${ }^{1}$ Virginia Tech, Department of Geography, ${ }^{2}$ University of Colorado Boulder, Institute of Behavioral Science, ${ }^{3}$ University of Colorado Boulder, Department of Anthropology, ${ }^{4}$ University College London, Department of Anthropology, ${ }^{5}$ Savanna Land Use Project, Tanzania 
Molina et al. 2017), social movements (Miller 2000, Peet and Watts 2004, Nicholls 2009), and social capital (Fine 1999, Adger 2010), which can be seen as the fruits of social connection. With this in mind, we review research in sociology on social tie formation.

\section{Mechanisms of tie formation}

Tie formation has been a popular area of study in many contexts. In their excellent review of the sociological research on dyadic ties, i.e., the connections between two individuals, Rivera et al. (2010) stratified connection mechanisms into three categories: (a) assortative mechanisms, which focus on actors' individual attributes; (b) relational mechanisms, which focus on the structure of actors' networks and their positions within them; and (c) proximity mechanisms that focus on actors' social and cultural contexts.

With assortative mechanisms, social connections are thought to be driven by individuals' attributes, which may include, gender, age, sex, race, ethnicity, religion, or education, among others. Two dominant and divergent hypotheses here are that, (1) people connect with others who have similar attributes, i.e., homophily; and (2) people connect with others who have dissimilar attributes, i.e., heterophily. Homophily is especially common in friendship (Van Duijn et al. 2003, Thomas 2019) and intimate relationships (Qian and Lichter 2007, Lambert and Griffiths 2018) where similarities are understood to promote trust and mutual acceptance, and reduce conflict (McPherson et al. 2001, Currarini et al. 2016). Alternatively, heterophily often characterizes collaborative groups where diverse skills and backgrounds are needed to confront complex challenges (Page 2008, Xie et al. 2016).

With relational mechanisms, social connections are thought to be driven by the structure of social networks, and individuals' positions within them. Analyses, typically quantitative, expand beyond direct ties to include indirect ties, or connections' connections. Key hypotheses here relate to reciprocity, repetition, clustering, and degree centrality, i.e., the number of ties a person has. First, people generally reciprocate offered relationships because they tend to like people who like them (Montoya and Insko 2008). Second, people tend to form repeated ties with each other over time because of trust and social embeddedness in forming ties (Baldassarri 2015, Pan et al. 2017). Third, people tend to cluster, or more colloquially to become friends with their friends' friends, in part because people who spend time with a shared third-party are likely to incidentally encounter each other (Granovetter 1973).

Last, proximity mechanisms focus on the effects of actors' social and cultural environments. Rivera et al. (2010) noted that the most basic hypothesis here is that interaction increases with geographic proximity, which has been supported in many contexts (Marmaros and Sacerdote 2006, Kleinbaum et al. 2008, Arentze et al. 2012). But the concept of proximity is not limited to physical distance (Gieryn 2000). Social interactions are organized around myriad social, physical, economic, and legal institutions that exist in time and space (Feld 1981). People connect through the groups they spend time with, at work, through leisure time, in their communities, and elsewhere (Grossetti 2005).

Despite the abundance of research on tie formation, we are aware of no studies that have examined technology-mediated social tie formation in rural areas of the Global South. As noted above, this study focuses on a new type of social tie, one formed through wrong numbers, and its association with livelihoods among Maasai communities in northern Tanzania.

\section{CONCEPTUAL FRAMEWORK}

As traditionally mobile pastoralists living in ethnically dense, rural areas, Maasai exemplify the characteristics of strong ties found in tightly bonded, relatively homogenous social networks (Gittell and Vidal 1998) that exhibit relational, assortative, and proximity tie mechanisms, often in culturally prescribed ways. Specifically, Maasai clan and age-set social institutions are critical and longstanding reservoirs of social capital and adaptive capacity for resilient livelihoods. But Maasai life has changed greatly over the past several decades (Spear and Waller 1993, Homewood et al. 2009). The adoption of new identities (Hodgson 2011) and new economic activities, including agriculture and wage-labor migration (McCabe et al. 2010, 2014), have spurred the famously insular Maasai into greater engagement with political processes, the market economy, and new weak ties with outside groups (Baird 2014). And in the past decade, these shifts have been attended by the rapid adoption of mobile phones throughout Maasailand (Msuya and Annake 2013, Butt 2015).

Studies of mobile phone adoption and use in rural East Africa have found that phones can support a range of livelihoods, including pastoralist and agricultural land uses by improving information exchange, market integration, access to emergency services, mobile banking, and human-wildlife conflict (Msuya and Annake 2013, Butt 2015, Lewis et al. 2016, Baird and Hartter 2017, Quandt et al. 2020, Krell et al. 2021). Notably women's experiences with phones are more constrained (Summers et al. 2020). We are aware of no research that has examined tieformation in this context.

To examine the issue of wrong numbers within this group, we adopt a conceptual framework that views, (1) social ties as the basis of social networks; (2) technology as a mediator of social ties; and (3) technology-enabled errors as drivers of new weak ties, which we refer to as wrong number connections (WNCs).

Within our framework, the importance of social ties to Maasai is seen as evolving with the ongoing livelihood diversification of the pastoralist economy into privately held and managed agriculture, off-farm employment, and wage-labor migration, among other activities. A consequence of this trend is that households can benefit from new types of information, which may not be available within their immediate social networks. Disinformation and fraud are also propagated through mobile phones and users must be vigilant (Archambault 2011, Hahn 2012, Baird and Hartter 2017). Still, people seek to connect with new individuals and groups to acquire new types of information and learn about new opportunities. Mobile phones can dramatically reduce the barriers to communication, but questions remain about whether they can be used effectively to stimulate new social ties (Donner and Escobari 2010, Marler 2018). Despite the abundance of mobile phones in rural areas, there may be few opportunities for novel social ties. This, in fact, could be a new chokepoint for rural residents wishing to branch out socially and economically. In this context, WNCs can be seen as an innovation in social networking with implications for livelihoods and land use across wide areas. 
This conceptualization points to three general research questions: (RQ1) Under what conditions are WNCs formed, and with what outcomes? (RQ2) What is the incidence of WNCs in the study area? (RQ3) How are WNCs associated with livelihoods, controlling for other factors?

\section{METHODS}

\section{Study site}

This study was conducted in 10 study communities in Longido and Simanjiro districts in northern Tanzania. Figure 1 shows five communities north of Arusha (Longido district) and five to the south (Simanjiro district). These areas are well suited to examine the effects of nascent mobile-phone use on social networks and livelihoods in rural, developing areas. First, these rural districts are predominantly ethnically Maasai (Mackenzie et al. 2014), which reduces variance along cultural lines. Second, phone-use is common in each area despite variable mobile signal (Lewis et al. 2016, Baird and Hartter 2017, Summers et al. 2020). Third, compared to many other groups, Maasai have more homogenous, tightly bonded social networks where members share many attributes (Patulny and Lind Haase Svendsen 2007, Borgatti et al. 2009, Baird and Gray 2014). Over many decades, Maasai have maintained longstanding traditions of polygyny, age-set and clanbased social organization, and forms of mobile pastoralism, even as they engage with external ideas and practices through formal education, agriculture, and Christianity (Leslie and McCabe 2013, Baird 2015, Woodhouse and McCabe 2018, McCabe et al. 2020).

Fig. 1. Map of the study area in northern Tanzania with study village centroids (Longido district villages north of Arusha; Simanjiro district villages south of Arusha).

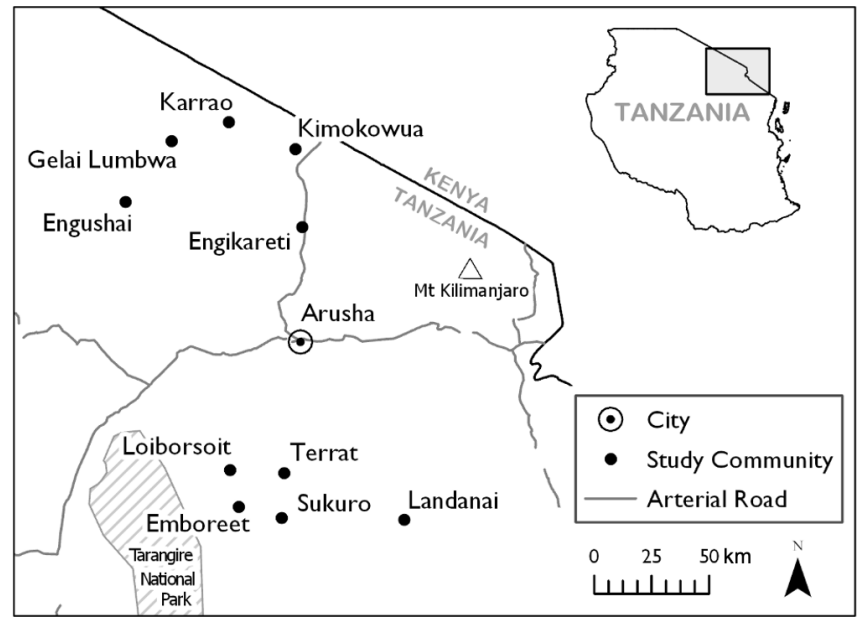

Some differences between the districts are also evident. Importantly, agriculture is much more common in Simanjiro, where rainfall is inconsistent but generally higher than in Longido. Land-based tensions surrounding agriculture and land leasing there have grown over many years, prompting outside NGOs to collaborate with communities to protect traditional communal grazing areas in the study communities (Nelson et al. 2010). Also, residents in Simanjiro appear to have better cellular signal and spend more money using their phones than residents in Longido.

\section{Data collection}

Our data collection proceeded in several steps. To begin, we conducted group interviews $(n=18)$ with male and female community members and leaders in five study communities: (1) to learn about respondents' patterns of phone use; (2) to assess the ways that phone use is associated with the maintenance and development of social networks; and (3) to inform the development of standardized surveys of men and women. Group interviews were stratified by gender. Through these steps, conducted in 2018, we first learned that WNCs occur and were not necessarily rare among men (RQ1). However, women informed us unequivocally that they (women) do not create these types of connections, largely because men often control women's use of phones (Summers et al. 2020). Based on these qualitative insights we included a question about WNCs on our men's survey (RQ2 and RQ3). Results from this survey led us to conduct a set of follow-up group interviews $(n=7)$ with men in 2019 to learn about the specific circumstances surrounding the formation and development of WNCs (RQ1).

Group interviews allowed for open discussion around broadly framed questions about mobile-phone use and social networks, as well as the causes and consequences of WNCs. For the initial interviews in 2018 we recruited participants from a range of socioeconomic backgrounds in multiple sub-villages within the study area. These interviews solicited information about how social networks are changing, whether phones are affecting social networks, and how phones are contributing to decision making. A key question during these interviews was whether respondents met new people through their use of mobile phones, a question we have asked groups since 2014. Mostly, people responded that they did not, except in certain cases like children's school-teachers. However, once we learned of WNCs in 2018 and began asking about it, respondents confirmed its existence and provided personal examples. In 2019, we conducted seven follow up interviews with groups of participants who had formed WNCs. We asked respondents to describe their WNCs, including the number, their locations, why they are important, how they use them to manage problems, and whether they have caused new problems. We also interviewed several respondents, in group settings, about their decisions not to pursue WNCs (RQ1).

To collect quantitative data on the incidence of WNCs in the study area (RQ2) and other factors (RQ3), we conducted a structured survey of household heads, who are typically male, in 10 study communities $(n=317)$ in 2018 . In each district, we surveyed respondents who have participated in longer term research projects run by the authors. The sample in Simanjiro, which was started in 2005 and has been added to intermittently, is based on a quota sampling strategy (Bernard 2017) to create a representative sample. Local leaders have helped us to identify the following: (1) households from different administrative units (in proportion to the size of the unit); (2) household heads from each Maasai age-set; and (3) households representing a spectrum of wealth statuses (proportional to local distributions of wealth, where herd size is used as an observable and reliable indicator of wealth). The sample in Longido, was drawn randomly from village registries in 2017 for a related project. Trained Maasai enumerators conducted the survey with household heads between September and December 2018. "Households," referred to as olmarei in Maa, the Maasai language, include a household head 
and his/her dependents, which may include multiple wives (in the case of male heads), and their children, grandchildren, parents, siblings, and even non-relatives residing with the family (Homewood et al. 2009).

Survey data provided detailed information about each respondent including his household, livelihood activities, and phone use. Respondents were asked about communication with WNCs according to two strata: on the phone and face-to-face. For each stratum, respondents were asked whether they had communicated with a WNC in the past 7 days, in the past 4 weeks, more than 4 weeks ago, or never. These questions, used elsewhere (Baird and Hartter 2017), provide a measure of both the incidence of WNCs in the study sample and the relative importance of these connections for individuals. Other survey measures included each respondent's age, education, household demographics, land allocations, and multiple measures of wealth and economic productivity.

\section{Data analyses}

Our analyses of WNCs proceeded in multiple steps. The first set of qualitative analyses describe the conditions under which WNCs are created, what forms these connections take, and what outcomes they yield (RQ1). The second set of analyses use quantitative approaches to show the incidence of WNCs in the study population (RQ2) and examine the factors associated with them (RQ3).

\section{Qualitative analyses}

We conducted content analysis of group interview responses to describe how WNCs are formed. Specifically, we inductively coded 16 group interview transcripts (Bernard 2017), from 2018 and 2019, using qualitative analytical software (Atlas.ti). Our interpretation of these interview responses was supported by insights gained through many years of working with these study communities examining issues of land-use, livelihood change, and mobile phone use.

\section{Quantitative analyses}

We estimated three main regression models, using Stata/IC 15.1, to examine the association between WNCs and measures of livelihoods (RQ3). For dependent variables, we used measures that interview respondents associated directly or indirectly with WNCs (described in the qualitative results): (1) herd size (i.e., a proxy for pastoralist livelihood activities); (2) total acres cultivated (e.g., agricultural livelihood activity); and (3) land leased (e.g., generally to people outside the community for agriculture). For these variables, we fit Poisson, multiple logistic, and logistic regression models, respectively. And in each model, we adjusted for clustering at the level of the village (Angeles et al. 2005). Our main explanatory variable was a simple dichotomous measure of WNC indicating whether the respondent had ever had a WNC, defined as a connection made through a wrong number where the respondent had saved the phone number and corresponded with the connection multiple times. We also examined an alternative specification of this variable: whether the respondent had ever met with a WNC face-to face, indicating an especially strong connection.

Table 1 provides descriptions and means for all the variables in the models, including means stratified by district. Independent variables included traditional covariates of land use among
Maasai pastoralists: the age and education level of the household head, household size, land allocation, and herd size, a conventional measure of pastoralist wealth (Homewood et al. 2009, Baird and Gray 2014). Notably, herd size was not included as a predictor in the model of herd size. We also included two measures of mobile phone access and use: voucher purchases and mobile-phone signal quality (Lewis et al. 2016).

Strengths and weaknesses of the approach

This study approach has several strengths. First, our research team has worked in these communities for many years, and the quality of our relationships in the study site strengthened the quality of our data collection efforts. Second, our mixed qualitative and quantitative approach combines the strengths of both types of data. Qualitative data helped us to understand how the phenomenon occurs and characterize some of the causal mechanisms associated with WNCs. Quantitative data allowed us to quantify the incidence of WNCs and test their relationships with other factors to make generalizations across our study site.

The central weakness of our approach is that we did not ask survey respondents about the number or timing of their WNCs. We do not know how many WNCs each respondent has or whether the relationships were formed in the 12 months before the survey was conducted, which is the time period over which our dependent variables were measured, or more than 12 months ago. In short, our quantitative survey data do not measure the timing of WNCs, however our qualitative interviews provide evidence of causal mechanisms and support their use as the primary independent variable.

\section{RESULTS}

\section{Qualitative results}

How are connections made?

Connecting through a wrong number is relatively straightforward, but involves multiple steps. First, an individual dials a number incorrectly. This may result from writing a number down incorrectly to begin with, or simply mis-keying a number in the phone, each of which can stem from low levels of literacy, as noted by our respondents. Furthermore, the likelihood of these errors may be increased by the common practice of using a friend's phone when one's battery is dead. Second, the receiving party answers the phone in a specific language, signaling to the caller something about the receiver's identity. Third, the error is quickly identified. Fourth, the parties either end the call swiftly or they do not. In some instances, individuals may chat for a while, especially (but not exclusively) if the receiver answers in Maa. Maasai social institutions can help members, who may be far from each other geographically, find common ground and mark their social position relative to each other. This type of social scaffolding is not present when the receiver is non-Maasai, but connections can be made nonetheless. Fifth, when the call ends one or both of the individuals may save the contact number for use later. Ultimately, the social connection takes root and grows if/when the individuals maintain contact with each other, and, in some cases, elect to meet each other face-to-face. There can be variations to this general scenario, which we discuss below.

Phone plans themselves can also serve as a mechanism for WNCs. People commonly purchase phone companies" "bundles," which 
Table 1. Descriptions and means for variables used in regression analyses, including means stratified by district and significance tests for difference in district means. $\mathrm{WNC}=$ wrong number connections.

\begin{tabular}{|c|c|c|c|c|c|}
\hline \multirow[t]{2}{*}{ Variable } & \multirow[t]{2}{*}{ Description } & \multicolumn{3}{|c|}{ Means } & \multirow[b]{2}{*}{$\begin{array}{l}\text { Longido vs } \\
\text { Simanjiro }\end{array}$} \\
\hline & & $\begin{array}{c}\text { Full } \\
\text { sample }\end{array}$ & Longido $^{\dagger}$ & Simanjiro $^{\dagger}$ & \\
\hline \multicolumn{6}{|l|}{ Dependent variables } \\
\hline TLUs $^{\S}$ & $\begin{array}{l}\text { Number of tropical livestock units (measure of livestock } \\
\text { holdings that accounts for differences across species) in the } \mathrm{HH} \\
\text { (household) }\end{array}$ & 39.36 & 29.84 & 45.43 & * \\
\hline Total acres & $\begin{array}{l}\text { Total acres cultivated by the } \mathrm{HH} \text { in the past } 12 \text { months (models } \\
\text { include a } 3 \text {-strata categorical measure; for Longido: acres }=0 \text {, } \\
\text { acres }>0 \text { and } \leq 3 \text {, acres }>3 \text {; for Simanjiro: } 0, \leq 10,>10 \text { ) }\end{array}$ & 7.79 & 1.79 & 11.61 & $* * *$ \\
\hline Leased land $(0 / 1)$ & $\mathrm{HH}$ leased land to another person in the past 12 months & 0.17 & 0.07 & 0.24 & $* * *$ \\
\hline \multicolumn{6}{|l|}{ Independent variables } \\
\hline WNC (phone) $(0 / 1)$ & $\begin{array}{l}\text { Household head (HHH) has corresponded with WNC by } \\
\text { phone }\end{array}$ & 0.46 & 0.24 & 0.60 & $* * *$ \\
\hline WNC (face-to-face) $(0 / 1)$ & HHH has corresponded with WNC face-to-face & 0.14 & 0.11 & 0.17 & \\
\hline \multicolumn{6}{|l|}{ Individual controls } \\
\hline Age & Age of $\mathrm{HHH}$ & 50.60 & 47.55 & 52.56 & \\
\hline Education $(0 / 1)$ & HHH has completed primary school (i.e., Standard 7) & 0.35 & 0.34 & 0.37 & \\
\hline \multicolumn{6}{|l|}{ Phone controls } \\
\hline Vouchers $(0 / 1)$ & HHH spent $2500 \mathrm{TSh}$ or more in the past 7 days & 0.38 & 0.33 & 0.40 & \\
\hline Signal $(0 / 1)$ & $\begin{array}{l}\text { HHH ranked phone signal quality as "very good" in sub- } \\
\text { village }\end{array}$ & 0.54 & 0.46 & 0.59 & * \\
\hline \multicolumn{6}{|l|}{ Household controls } \\
\hline Household size & Number of individuals living in the $\mathrm{HH}$ & 13.70 & 16.10 & 12.17 & $* *$ \\
\hline $\mathrm{TLUs}^{\S}$ & $\begin{array}{l}\text { Number of tropical livestock units (measure of livestock } \\
\text { holdings that accounts for differences across species) in the } \mathrm{HH}\end{array}$ & 39.36 & 29.85 & 45.43 & $*$ \\
\hline Land allocation & $\begin{array}{l}\text { Number of acres of land allocated by village governments to } \\
\text { HHs for private use, typically agriculture }\end{array}$ & 23.04 & 13.45 & 29.15 & $* * *$ \\
\hline
\end{tabular}

provide heavy discounts on a variety of different service packages (e.g., minutes, SMS, data, etc.) for a fixed time period (e.g., one day, week, or month). For example, a bundle may provide 200 minutes of calling during a 7-day period for a discounted price. To avoid losing unused minutes, we learned that as people near the end of their bundle's time period, some use available minutes to call back unusual numbers in their incoming call-log, which they had not answered. Similarly, Maasai get call-backs from people they wrongly dialed days before.

Last, individuals can also dial wrong numbers intentionally. Respondents described how some people, typically younger men, may intentionally substitute a single number, as an example, just to see who they get.

During our interviews, participants regularly received calls and nearly always answered the call, generally stepping away from the group until the call was over. This happened dozens of times over many meetings. And on a few occasions, the individual returned to the group and announced that the call was a wrong number.

With whom are connections made?

Through personal descriptions of their WNCs, our respondents showed that they connect with several types of people. Unsurprisingly, connections with other Maasai were common. One scenario here is that the callers begin the call speaking Maa. With a wrong number, shared ethnicity represents an important shared attribute. In these situations, respondents described how they would typically proceed to learn about the stranger. First, the parties would exchange family names, i.e., their fathers' names, then their physical locations, clans, and age-sets. "Then," one respondent noted, "you know how to control the conversation." Sharing these characteristics helps callers to identify other points of connection and inserts a culturally prescribed set of conversational norms based on social position.

Our respondents described these connections with other Maasai affectionately. People noted how Maasai are very close, that this is something they value and "when you find a Maasai, you develop this connection." In a group interview with older men, one noted that "Maasai are good at hospitality. They have been this way since the beginning." Respondents also described how they have discovered relatives through wrong numbers. During one meeting, a respondent received a wrong number call from another Maasai he had never met, and over a short conversation learned that their fathers were brothers. It was an astonishingly timely example of what we had been discussing. (That cousins would not have known about each other is not necessarily unusual in a society where polygynous families can be very large, and extended families exponentially so.)

Our respondents also described numerous WNCs with nonMaasai from a range of other ethnic groups, geographic locations, and livelihoods. Figure 2 shows the locations of WNCs that respondents described during our interviews. In multiple 
meetings, we asked if there were any groups that Maasai seek to avoid when it comes to WNCs. Responses were unequivocal. We were told that they were willing to connect with any group, that only the individual and the conversation mattered.

Fig. 2. Map of the locations of wrong number connections described during group interviews.

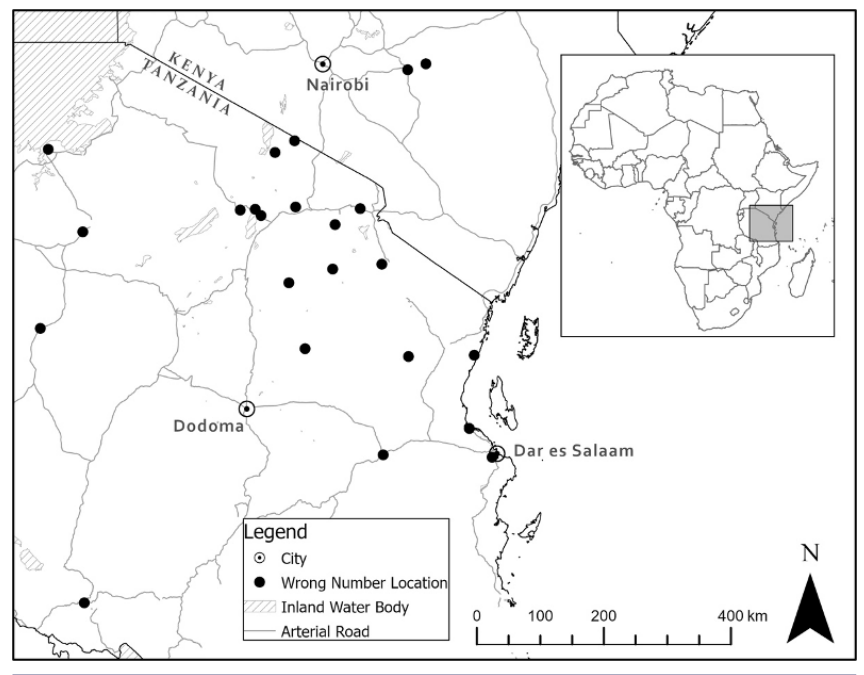

An important note here is that WNC participants each need to be willing to connect and engage in maintaining the connection. Several respondents shared stories of initial connections followed ultimately by unrequited communication. Connections form, some flourish, but many atrophy and die. This raises the important questions: why do people connect in the first place?

Why are connections made?

When asked why connections are made, and specifically why they are important, respondents shared several motivations for, and benefits of, WNCs. As one respondent noted, "good things happen." Their descriptions of personal WNCs especially revealed why some Maasai welcome, and even seek these types of connections. Here, we organize their examples according to broad thematic categories that reflect common Maasai concerns: information, land-based resources, and reciprocity. It is important to note that while these are presented as discrete categories, they overlap in various ways.

Information: One respondent summed up Maasai interest in WNCs simply. He described how he had called a wrong number in Mbeya in the far south of Tanzania. The man, a non-Maasai, called two days later and they connected. The respondent had never been to Mbeya, but stated, "Now I can know." Respondents repeatedly expressed how they value learning about other people and places. Intuitively, these relationships begin with each party gathering information. And for households and communities facing uncertain environmental and economic circumstances, information can serve as a critical resource.

Given Maasai pastoralists' long reliance on social networks and mobility to support their livelihoods, it was unsurprising that the most common responses to our question of why people make WNCs were making new friends and gathering information about the environmental conditions in distant areas. Indeed, many of the WNCs we learned about simply involved staying in touch and chatting about the weather and the condition of livestock in each area. But some respondents also noted that developing connections in distant areas can be useful if they, or a friend or family member, ever travel to that area in the future. In one example, a respondent described how he had made a WNC with an individual living in a village to which his sister had recently moved to be with her new husband and his family, as is customary. Through this WNC, the man reported that he was able to provide his sister with a potentially valuable social tie in this otherwise unfamiliar place.

Gathering information can also include prospecting for employment or business opportunities, including opportunities to gain access to land for grazing and crop-based agriculture, which we discuss below. Young men especially, we were told, save wrong number contacts in the event that they might one day be useful.

Land-based resources: Information itself can be an important resource, but it can also serve as a gateway to other resources. Respondents described how WNCs have facilitated access to important land-based resources, especially livestock forage, agricultural land, and non-timber forest products.

Several groups noted that discussions of weather and livestock conditions with WNCs can lead to critical movements of livestock to grazing areas during challenging times. One individual described how, during a drought in Simanjiro, he was able to move his livestock to a distant community in the west to access forage. He noted that as an outsider it would be illegal for him to move his animals there, but the WNC pretended the animals were his own. Ultimately, these animals survived where many others that remained in Simanjiro did not. Other respondents had similar stories and knew of people in their communities who had used WNCs to help organize livestock movements during times of scarcity.

Respondents also highlighted how WNCs can facilitate access to land for agriculture, for either party. One described how he was able to get land through a WNC in a village south of his only to lose it later when a game reserve was set up. In another case, respondents told of two men in their village who gained access to land for farms in a distant village, where they first brought their livestock to access forage, through the WNC. (In these examples, it was not stated whether these were leases or land allocations.) Perhaps more commonly, WNCs have sought agricultural land within the study area. Many groups in Simanjiro expressed that when WNCs learn they have reached someone in Simanjiro they often ask about land. In some cases, people end up leasing land to their WNCs. In one example, a respondent shared how he dialed a wrong number years ago, became friends with the WNC, and now leases him land to farm. In another, a man shared an example, from his village, of a WNC from the south of Tanzania who traveled to Simanjiro, leased land to farm, and began work in the Mererani mining sector, where many Maasai have been successful.

A few respondents also described how WNCs can be drawn into local communities in search of non-timber forest products. In one case, a WNC from the Kilimanjaro area was looking for certain types of wood that our respondent had access to. The WNC traveled to the respondent's village and paid both the village and 
the respondent to harvest some of the wood. Another example involved a special plant-based medicine that the respondent has been able to sell to the WNC on a recurring basis. He now sends shipments of the plant on the bus to Dar es Salaam (Dar).

Reciprocity, exchange, and employment: WNCs also serve to expand customary social networks in prescribed ways. In two meetings, individuals shared how they had arranged marriages for their sons with the daughters of their WNCs. Others noted that some people have formalized new friendships with Maasai WNCs by physically meeting each other and customarily exchanging livestock. Multiple groups shared stories of WNCs seeking consultation from traditional Maasai political and spiritual leaders (i.e., laigwanani and laibonok), often to help resolve difficult social conflicts in distant communities. In these cases, WNCs were from ethnic groups that share the Maa language and other cultural attributes, specifically Arusha and Parakuyu.

In other cases, respondents described using WNCs simply to manage and expand their social networks. Some shared how they have used WNCs to reach out to old, out-of-touch contacts who may live near the WNC. Others described traveling to meet WNCs in places like Arusha or Moshi, hours away by bus. One leveraged a WNC with a powerful position in Dar to facilitate government paperwork for another friend. And in some cases, WNCs can lead to new employment opportunities. A man in Simanjiro shared how he made a WNC near the coast who was looking to invest in improved livestock breeds. The man visited the WNC to inspect his herd and consult on potential breeds. He ended up traveling with his WNC to Kenya to purchase animals, efforts for which he was compensated. Another described a WNC he made in Dar who was looking to invest in livestock. The two men met in Arusha and ultimately set up a business buying livestock in the west and selling them in northern markets. One respondent received a wrong number call from an Indian-Tanzanian who ultimately invited the man to work for him as a guard in Dar, which he did for six months. Groups in Longido District also described how WNCs can lead to employment opportunities, especially in Nairobi.

\section{Concerns and challenges}

Although respondents described many potential benefits associated with WNCs, they also highlighted several concerns and challenges. A growing challenge surrounding WNCs involves land. In several interviews we conducted in Simanjiro, respondents explained how WNCs can be especially interested in gaining access to land. This issue was framed in both positive and negative ways. Multiple individuals shared how they had welcomed a WNC into the village, either to farm or conduct other business. They described how these outsiders had brought benefits to them and in some cases their communities. When asked whether people were concerned that outsiders who get a foothold in the village may help other outsiders to come, many respondents agreed that this was becoming a big problem, especially given the difficulty even local people face accessing land. According to respondents, outsiders come, some through WNCs, and start a farm or a small shop, then they bring more family members and ultimately enroll their children in school to become official members of the village, then they seek more land. We were told that when some WNCs learn that they have reached someone in
Simanjiro, they will call repeatedly, badgering the individual about land.

The most common challenge, according to our interviews, involves scams. Many respondents explained that they do not "follow" wrong numbers because of the prevalence of phonebased scams, which can take many forms. Mysterious callers may offer get-rich-quick schemes, disease cures, or miraculous plans to find love or fame. Another example involves callers who actually know the receiving party's name. Although these calls may or may not present as wrong number calls, they nonetheless cast a shadow over phone-based communication for many people, steering them away from WNCs. Since 2019, Tanzania has implemented a national phone registry, including biomarkers, in an effort to root out these types of fraud.

Others described how, unlike strong ties, valuable WNCs can disappear in an instant. Two types of examples were offered here. First, WNCs can arrange to meet at a specific time and place, generally at a distant location, but at the appointed time one party fails to show and then never responds. We heard examples of this in the contexts of missed employment opportunities and aborted rendezvous between men and women. The second type involves the simple loss of one's phone and all its contacts. We heard multiple stories from people with positive, ongoing WNCs who lost their valuable weak ties in this way.

\section{Quantitative results}

Table 1 presents basic descriptive statistics for all the variables used in our quantitative analyses, including variable means stratified by district. First, it shows that livelihood measures vary significantly between the districts, with average respondents in Simanjiro having larger herds, farming more, and being more likely to lease land compared to respondents in Longido. Next, $46 \%$ of all respondents have had a WNC, and the difference between districts is significant with $60 \%$ in Simanjiro compared to $24 \%$ in Longido (RQ2).

The stratified means for several independent variables are also significantly different. Not accounting for other factors, respondents in Simanjiro were more likely to rank their cellular signal as "very good," have smaller household sizes, and larger land allocations than respondents in Longido. Notably, the average age of our respondents and their rates of basic education do not vary significantly between districts.

Table 2 presents the results of the regression analyses of the association between WNCs and measures of land use, stratified by district and controlling for other factors (RQ3). For the Poisson regression model of $T L U s$, incidence rate ratios represent the factors by which $T L U s$ would be expected to increase (for factors greater than 1) or decrease (for factors less than 1) given a 1 unit increase in continuous predictor variables, or moving from 0 to 1 for dichotomous variables, given that the other variables in the model are held constant. For the multiple logistic model of total Acres cultivated (two columns), relative risk ratios represent the factors by which the relative risks of cultivating a low (Acres low column) or a high (Acres high column) number of acres compared to zero acres (referent category) would, again, be expected to increase or decrease given a 1 unit increase in continuous predictor variables, or moving from 0 to 1 for dichotomous variables, given that the other variables in the model are held constant. Broadly, 
Table 2. Variable incidence rate ratios, relative risk ratios, odds ratios and significance tests for Poisson, multiple logistic, and logistic regression models of livelihood measures in the prior 12 months. WNC $=$ wrong number connections; TLUs $=$ tropical livestock units.

\begin{tabular}{|c|c|c|c|c|c|c|c|c|}
\hline \multirow[b]{2}{*}{ Predictors } & \multicolumn{4}{|c|}{ Longido district } & \multicolumn{4}{|c|}{ Simanjiro district } \\
\hline & $\mathrm{TLUs}^{\dagger}$ & Acres $(\text { low })^{\dagger}$ & Acres (high) & Leased land $^{\S}$ & $\mathrm{TLUs}^{\dagger}$ & Acres $(\text { low })^{*}$ & Acres (high) $)^{\ddagger}$ & Leased land $^{\S}$ \\
\hline \multicolumn{9}{|l|}{ Explanatory variable } \\
\hline WNC, phone $(0 / 1)$ & 1.17 & 2.06 & 1.38 & 1.12 & 0.69 & 0.82 & 0.63 & $6.19 * * *$ \\
\hline \multicolumn{9}{|l|}{ Individual controls } \\
\hline Age & 0.99 & $1.02 *$ & 0.99 & 1.00 & 1.00 & 1.00 & 1.01 & $1.00 * *$ \\
\hline Education $(0 / 1)$ & 1.04 & 0.07 & 1.09 & 1.29 & 1.49 & 0.20 & $0.29 * *$ & 1.31 \\
\hline \multicolumn{9}{|l|}{ Phone controls } \\
\hline Phone vouchers $(0 / 1)$ & $1.47^{*}$ & 0.34 & 1.25 & 0.46 & $2.25 * * *$ & $1.98 *$ & 1.77 & $0.20 * *$ \\
\hline Best signal (0/1) & 1.04 & $7.80 * * *$ & 0.96 & 0.90 & 0.86 & 1.07 & 1.55 & 0.70 \\
\hline \multicolumn{9}{|l|}{ Household controls } \\
\hline $\mathrm{HH}$ size $(\ln )^{\mid}$ & $1.81 * *$ & $0.11 * * *$ & 1.68 & 0.59 & $2.34 * * *$ & $0.48 *$ & 1.13 & $1.84^{*}$ \\
\hline TLUs $(\ln )^{\mid}$ & & 0.98 & 1.26 & 1.77 & & 0.96 & 1.52 & 0.88 \\
\hline Land allocation $(\ln )^{\mid}$ & $1.32 * * *$ & $2.92 * * *$ & 1.14 & 1.50 & 0.97 & $1.19^{* *}$ & 1.38 & 1.23 \\
\hline $\begin{array}{l}\mathrm{n}_{\text {households }} \\
\text { Alternative specification }\end{array}$ & 118 & 118 & 118 & 118 & 180 & 180 & 180 & 180 \\
\hline WNC, face-to-face $(0 / 1)$ & 1.49 & 6.46 & 2.00 & 1.55 & 0.98 & 0.91 & 1.07 & 1.01 \\
\hline \multicolumn{9}{|c|}{$\begin{array}{l}\text { Reference categories are no acres planted (for Acres models), less than Standard } 7 \text { education, did not spend } 2500 \text { Tanzania shillings (TSh) on phone } \\
\text { vouchers in } 7 \text { days prior to survey, and did not rank sub-village phone signal as "very good." }\end{array}$} \\
\hline
\end{tabular}

relative risk ratios greater than 1 indicate greater likelihood to farm (i.e., low or high Acres) than not to (i.e., zero Acres). For the logistic regression model of Leased land, odds ratios represent the factors by which the odds of Leased land would be expected to increase or decrease given a 1 unit increase in continuous predictor variables, or moving from 0 to 1 for dichotomous variables, given that the other variables in the model are held constant.

Our analyses showed one significant association with $W N C$. Controlling for other factors, respondents in Simanjiro who have, or have had, a $W N C$ were approximately six times more likely to have Leased land in the past 12 months than respondents who have never had a $W N C$. In Longido, $W N C$ was not significantly associated with any land-use measures. Lastly, there were no significant associations between dependent variables and the alternative specification, WNC (face-to-face), in either district.

Several control variables were also significantly associated with our measures of land use. Phone vouchers and Household size were positively associated with TLUs in each district. And Land allocation was positively associated with TLUs in Longido. Also in Longido, Age, Best signal, and Land allocation were each positively associated with Acres (low) indicating that older respondents, those with the best signal, and those with larger land allocations were more likely to farm three or fewer acres (Low) in the prior 12-months than to not farm, which was also negatively associated with $\mathrm{HH}$ size. In Simanjiro, Phone vouchers and Land allocation were each positively associated with cultivating a low number of Acres (low) (ten or fewer), compared to not farming, whereas $H H$ size was negatively associated. Also in Simanjiro, primary Education was associated with a lower likelihood of farming 10 or more Acres (high) compared to not farming. And Phone vouchers were negatively associated with Land leasing, while $H H$ size was positively associated.

\section{DISCUSSION}

As far as we know, the qualitative results presented here describe a mechanism of tie formation in social networks that has not been examined in any academic literature, one that is enabled by mobile phones and driven by human error. Here, a constellation of technological, infrastructural, economic, and social factors, distinctly characteristic of rural areas in the Global South, create the conditions for error, or novelty, and in some cases these errors are seized on. People make WNCs with others from distant locations and diverse ethnic backgrounds. These connections are used to share information, shape movements and mobilities, and stimulate exchange and reciprocity across wide areas (RQ1).

Furthermore, WNCs are not rare. Nearly half of our sample have had at least one WNC in the past, though differences between districts are significant (RQ2). In Simanjiro, $60 \%$ of respondents have had a WNC compared to $24 \%$ in Longido. And many respondents with WNCs report face-to-face contact, some likely traveling great distances to do so.

\section{Social ties}

These results hold broader implications for the scholarship surrounding social networks and mobile technologies in the Global South. Notably, many studies in both urban and rural contexts argue that information and communication technologies are rarely bridging technologies that connect people with different backgrounds, but are used more commonly as tools to catalyze communication within existing, tightly bonded groups (Donner 2006, Kobayashi and Boase 2014, Marler 2018). Here, amidst widespread use of phones to support bonding behavior with strong ties, we also find a rare example of bridging behavior with new weak ties, which contrasts somewhat with results that Maasai social networks have not been transformed by mobile phone use (Butt 2015, Baird and Hartter 2017). 
From the perspective of traditional social network analysis, WNCs are relatively independent of relational and proximity mechanisms of dyad formation (Rivera et al. 2010). Existing social ties and one's position within a network play practically no role in two people encountering each other through a wrong number. Neither does physical proximity, at least within the geographic extent of the phone carrier's network. Our results, however, seem to exemplify a type of assortative mechanism that integrates homophily and heterophily. Multiform heterogeneity describes how social ties may form between individuals who are simultaneously similar in some ways and different in others (Blau 1974). This indeed may characterize many WNCs. Shared attributes like language and ethnicity can engender trust, while divergent attributes like geographic location or professional expertise provide real economic value.

Our results also highlight the diverse social and economic roles that WNCs can play in Maasai lives. At a minimum, they lead to new weak ties in a society characterized by strong ties and social institutions. Age-set and clan-based structures specifically have long been foundations of Maasai resilience (Leslie and McCabe 2013, Baird and Gray 2014). New ties with WNCs expand and diversify Maasai networks, allowing individuals to gather new information, prospect for new opportunities, and respond to shocks. And in some cases, these relationships can help households gain access to distant resources. WNCs also embody a new mechanism of tie formation, a type of social network jump, wherein new and relatively rare, but important social ties are formed without a discernible intermediate tie or activity that confers significant bias (like meeting someone on a bus or plane). We are aware of no studies that examine social network tie formation expressly outside this context of path dependency.

\section{Land-based resources}

This discovery raises the question of how impactful WNCs are, especially materially. Our strategy here was guided by respondents' descriptions of how WNCs can serve as conduits to critical land-based resources, especially grazing areas and agricultural land. Controlling for multiple factors, including proxies of phone use, we found that WNCs were not significantly associated with land-use types, with one exception. In Simanjiro, where group interview respondents described leasing land to and from WNCs, people with WNCs were much more likely to have leased land in the 12 months prior to the survey (RQ3). What is striking here is that land leasing, which is typically used for monocrop agriculture, is both ascendant and controversial in this area.

Over many years, Maasai in Simanjiro have incorporated rainfed agriculture into their pastoralist livelihoods, creating numerous tensions in the process (McCabe et al. 2010, Baird and Leslie 2013, Woodhouse and McCabe 2018). First, advocates for biodiversity conservation have argued that conversion of grazing lands to agriculture harms ecosystems (Phalan et al. 2011). Second, as these pastoralists have become more sedentary (Fox et al. 2019) and rural population density has grown, pressures on land have compounded with many households struggling to secure tenure (Muyanga and Jayne 2014) and being generally intolerant of outsiders gaining access to local land. So it was notable on several occasions during our group interviews when participants described how WNCs can become quite interested when they learn that they have connected with someone from Simanjiro, a district known for vast tracts of land, and a recent history of agricultural expansion (Nelson et al. 2010).

The issue of causality is challenging here. On one hand, group interview respondents' descriptions of leasing land to WNCs, and otherwise using WNCs to, at times, support the activities of herding and farming, support the use of WNCs as the explanatory variable in our models. However, it is quite possible that an unmeasured individual characteristic like ingenuity, industriousness, or perhaps risk tolerance drives both WNC and our livelihood measures. Furthermore, we can imagine how success in diversified livelihoods could increase an individuals' likelihood to take a chance on a WNC. Attention to these hypotheses requires greater understanding of why people embrace WNCs, including psychosocial and economic factors, and more detailed data on the timing and characteristics of survey respondents' WNCs.

Taken together, our qualitative and quantitative results highlight a concern that WNCs may serve as a new mechanism for outsiders to gain access to land in rural communities where tensions over land are already high, a concern expressly noted during our group interviews. Land-use pressures and disputes strike at the heart of this social-ecological system. In this way, WNCs and land leasing represent a new challenge for environmental management, cultural change, and community resilience. A related and important new question is whether WNCs lead to land conversion, or social change, that would not likely have occurred otherwise. Also, do WNCs, which represent a type of exogenous multiform heterogeneity, increase volatility and accelerate change within the system?

\section{Path dependency and the adjacent possible}

In social networks, as with other networks, processes and patterns are the functions of prior conditions and contexts (Ghezzi and Mingione 2007). Path dependency has been described as a phenomenon whereby current outcomes are not simply products of current conditions, but of prior outcomes. Framed more simply, path dependency asserts that "history matters" (Schreyögg et al. 2011). To characterize this implicit artefact in social network research, we borrow and adapt from adjacent possible theory, first articulated by Stuart Kauffman (1996) to describe complexity in biological and other systems and leveraged by others to describe pathways of human creativity and innovation (Johnson 2011, Chhatre et al. 2012, Monechi et al. 2017). Adjacent possible theory argues that, at any given moment in time, progress can only accrue in prescribed ways, limited by its immediate context and the possibilities that are adjacent to this context. Innovations do not spring from giant leaps but from stepwise progress into adjacent possibilities. Distant connections cannot be made until the space between is first traversed.

Research on social networks is predicated on adjacency, though this language is rarely used. People make new connections through adjacencies: family, friends, work, church, clubs, groups, chatrooms, etc. These ties, and their ties, create the sampling frame from which new ties are drawn. Within this line of thinking, social ties result from these myriad biases that place us in our unique contexts, and determine our adjacencies. The existence of WNCs, disrupts this implicit maxim of social tie formation, and suggests instead that "jumps" to distant, unfamiliar points are not only tractable but common in certain contexts. 
The concepts of path dependency and the adjacent possible tell us that the future is limited by the past and the present. By prevailing against these constraints, WNCs should be expected to expand the range of potential system outcomes, all other things being equal, and increase volatility.

This hypothesis raises the question of randomness. Are WNCs random social ties? The best answer here is no. Randomness is complete unpredictability. Even genetic mutations are not random in a purely mathematical sense. Parallels here may merit further comparison. WNCs do reflect the broad evolutionary principles of mutation/selection or chance/choice. Chance occurrences, i.e., wrong numbers, provide opportunities for selection, i.e., chatting, saving the number, and maintaining engagement, based on the perceived utility of the connection for both parties, which may include access to distant information and material resources. Arguably, the initial exposure, or chance portion of this connection, is much more random than most exposures, which are typically governed by various biases. But the selection, or choice, portion of the connections adhere to typical assortative mechanisms, especially multiform heterogeneity as discussed above. As respondents noted, some new connections grow and thrive and others wither and die.

It may be that while the term "random ties" misrepresents and oversells the mechanism of social connection we have discovered, the term "accidental ties," which we use in the title of the paper, distinctly undersells the novelty of these social connections. Labels aside, the novelty of WNCs raises the question of whether they are idiosyncratic to Maasai, or perhaps groups whose strong social institutions embed social ties in a shared culture of trust. Curiously, through informal conversations with colleagues about these findings, we have heard anecdotes that WNCs occur in places like India and China, often with young people, though scarcity and opportunism, rather than trust are seen as drivers of connection. Notably, many WNCs described in this study are with non-Maasai Tanzanians and Kenyans, which points to new questions: Where else do WNCs occur? How do factors like gender, class, infrastructure, and culture affect whether people embrace or avoid WNCs in other places? How are livelihoods affected in WNCs' locations? What effects do WNCs have on household- and community-level resilience? And what other mechanisms of social connection are analogous to WNCs? Future research should examine these and related questions.

Responses to this article can be read online at: https://www.ecologyandsociety.org/issues/responses. $\mathrm{php} / 12528$

\section{Author Contributions:}

TB: conceptualization, methodology, formal analysis, investigation, data curation, writing - original draft, project administration, funding acquisition; JM: conceptualization, methodology, investigation, writing - review \& editing, funding acquisition; EM: conceptualization, methodology, investigation, writing - review \& editing, funding acquisition; IR: investigation, project administration; $S S$ : investigation, project administration; GS: investigation, project administration.

\section{Acknowledgments:}

This study was supported by grants from the U.S. National Science Foundation (BCS-1660428) and the Research Councils U.K. (ES/ R003351/1). We thank Kelly Summers, Felista Terta, and Naomi Peter for their assistance in the field. Also, we thank the Global South Studies Center at the University of Cologne for accommodation while TB was preparing this manuscript. Permission for this research was granted by the Tanzanian Commission for Science and Technology, local governments, and the Virginia Tech Institutional Review Board.

\section{Data Availability:}

The datalcode that support the findings of this study are available on request from the corresponding author, TDB. The datalcode are not publicly available because they contain information that could compromise the privacy of research participant. Policies regarding the disruption of these data are regulated by the Virginia Tech Institutional Review Board to ensure research subject protections, as well as the data management plan for this project approved by the Virginia Tech Libraries and supported by the U.S. National Science Foundation.

\section{LITERATURE CITED}

Adger, W. N. 2010. Social capital, collective action, and adaptation to climate change. Pages 327-345 in M. Voss, editor. Der Klimawandel. Springer, Wiesbaden, Germany. https://doi. org/10.1007/978-3-531-92258-4 19

Aker, J. C. 2011. Dial "A" for agriculture: a review of information and communication technologies for agricultural extension in developing countries. Agricultural Economics 42(6):631-647. https://doi.org/10.1111/j.1574-0862.2011.00545.x

Aker, J. C., and C. Ksoll. 2016. Can mobile phones improve agricultural outcomes? Evidence from a randomized experiment in Niger. Food Policy 60:44-51. https://doi.org/10.1016/j. foodpol.2015.03.006

Angeles, G., D. K. Guilkey, and T. A. Mroz. 2005. The impact of community-level variables on individual-level outcomes. Sociological Methods \& Research 34(1):76-121. https://doi. org/10.1177/0049124104273069

Apicella, C. L., F. W. Marlowe, J. H. Fowler, and N. A. Christakis. 2012. Social networks and cooperation in hunter-gatherers. Nature 481(7382):497-501. https://doi.org/10.1038/nature10736

Archambault, J. S. 2011. Breaking up 'because of the phone' and the transformative potential of information in Southern Mozambique. New Media \& Society 13(3):444-456. https://doi. org/10.1177/1461444810393906

Arentze, T., P. van den Berg, and H. Timmermans. 2012. Modeling social networks in geographic space: approach and empirical application. Environment and Planning A 44(5):1101-1120. https://doi.org/10.1068/a4438

Baird, T. D. 2014. Conservation and unscripted development: proximity to park associated with development and financial diversity. Ecology and Society 19(1):4. https://doi.org/10.5751/ ES-06184-190104 
Baird, T. D. 2015. Conservation implications of the diffusion of Christian religious ideals in rural Africa. Population and Environment 36(4):373-399. https://doi.org/10.1007/s11111-014-0222-3

Baird, T. D., and C. L. Gray. 2014. Livelihood diversification and shifting social networks of exchange: a social network transition? World Development 60:14-30. https://doi.org/10.1016/j. worlddev.2014.02.002

Baird, T. D., and J. Hartter. 2017. Livelihood diversification, mobile phones and information diversity in Northern Tanzania. Land Use Policy 67:460-471. https://doi.org/10.1016/j. landusepol.2017.05.031

Baird, T. D., and P. W. Leslie. 2013. Conservation as disturbance: upheaval and livelihood diversification near Tarangire National Park, northern Tanzania. Global Environmental Change 23 (5):1131-1141. https://doi.org/10.1016/j.gloenvcha.2013.05.002

Baldassarri, D. 2015. Cooperative networks: altruism, group solidarity, reciprocity, and sanctioning in Ugandan producer organizations. American Journal of Sociology 121(2):355-395. https://doi.org/10.1086/682418

Bernard, H. R. 2017. Research methods in anthropology: qualitative and quantitative approaches. Rowman \& Littlefield, Lanham, Maryland, USA.

Blau, P. M. 1974. Presidential address: parameters of social structure. American Sociological Review 39(5):615-635. https:// doi.org/10.2307/2094309

Borgatti, S. P., A. Mehra, D. J. Brass, and G. Labianca. 2009. Network analysis in the social sciences. Science 323 (5916):892-895. https://doi.org/10.1126/science.1165821

Butt, B. 2015. Herding by mobile phone: technology, social networks and the "transformation" of pastoral herding in East Africa. Human Ecology 43:1-14. https://doi.org/10.1007/ $\underline{\text { s10745-014-9710-4 }}$

Castells, M., M. Fernández-Ardèvol, J. L. Qiu, and A. Sey. 2009. Mobile communication and society: a global perspective. MIT Press, Cambridge, Massachusetts, USA. https://doi.org/10.7551/ mitpress/4692.001.0001

Chhatre, A., S. Lakhanpal, A. M. Larson, F. Nelson, H. Ojha, and J. Rao. 2012. Social safeguards and co-benefits in REDD+: a review of the adjacent possible. Current Opinion in Environmental Sustainability 4(6):654-660. https://doi.org/10.1016/ j.cosust.2012.08.006

Currarini, S., J. Matheson, and F. Vega-Redondo. 2016. A simple model of homophily in social networks. European Economic Review 90:18-39. https://doi.org/10.1016/j.euroecorev.2016.03.011

Donner, J. 2006. The use of mobile phones by microentrepreneurs in Kigali, Rwanda: changes to social and business networks. Information Technologies \& International Development 3 (2):3-19. https://doi.org/10.1162/itid.2007.3.2.3

Donner, J., and M. X. Escobari. 2010. A review of evidence on mobile use by micro and small enterprises in developing countries. Journal of International Development 22(5):641-658. https://doi. org/10.1002/jid.1717
Duncombe, R. 2018. Digital technologies for agricultural and rural development in the Global South. CABI, Wallingford, UK. https://doi.org/10.1079/9781786393364.0000

Duncombe, R. A. 2014. Understanding the impact of mobile phones on livelihoods in developing countries. Development Policy Review 32(5):567-588. https://doi.org/10.1111/dpr.12073

Feld, S. L. 1981. The focused organization of social ties. American Journal of Sociology 86(5):1015-1035. https://doi.org/10.1086/227352

Fine, B. 1999. The developmental state is dead-long live social capital? Development and Change 30(1):1-19. https://doi. org/10.1111/1467-7660.00105

Fox, D. N., T. D. Baird, M. J. Stern, and S. Prisley. 2019. Where mobile groups settle: spatial patterns and correlates of Maasai pastoralist sedentarization in northern Tanzania. Applied Geography 112:102086. https://doi.org/10.1016/j.apgeog.2019.102086

Ghezzi, S., and E. Mingione. 2007. Embeddedness, path dependency and social institutions: an economic sociology approach. Current Sociology 55(1):11-23. https://doi. org/10.1177/0011392107070131

Gieryn, T. F. 2000. A space for place in sociology. Annual Review of Sociology 26(1):463-496. https://doi.org/10.1146/annurev. soc. 26.1 .463

Gittell, R., and A. Vidal. 1998. Community organizing: building social capital as a development strategy. SAGE, Thousand Oaks, California, USA.

Granovetter, M. S. 1973. The strength of weak ties. American Journal of Sociology 78(6):1360-1380. https://doi.org/10.1086/225469

Grossetti, M. 2005. Where do social relations come from?: A study of personal networks in the Toulouse area of France. Social Networks 27(4):289-300. https://doi.org/10.1016/j.socnet.2004.11.004

Haenssgen, M. J., and P. Ariana. 2017. The social implications of technology diffusion: uncovering the unintended consequences of people's health-related mobile phone use in rural India and China. World Development 94(Supplement C):286-304. https:// doi.org/10.1016/j.worlddev.2017.01.014

Hahn, H. P. 2012. Mobile phones and the transformation of society: talking about criminality and the ambivalent perception of new ICT in Burkina Faso. African Identities 10(2):181-192. https://doi.org/10.1080/14725843.2012.657862

Henrich, J. 2006. Cooperation, punishment, and the evolution of human institutions. Science 312(5770):60-61. https://doi. org/10.1126/science. 1126398

Hodgson, D. L. 2011. Being Maasai, becoming indigenous: postcolonial politics in a neoliberal world. Indiana University Press, Bloomington, Indiana, USA.

Homewood, K., P. Kristjanson, and P. C. Trench, editors. 2009. Staying Maasai: livelihoods, conservation and development in East African rangelands. Springer, New York, New York, USA.

Horst, H., and D. Miller. 2006. The cell phone: an anthropology of communication. Berg, Oxford, UK. 
International Telecommunication Union (ITU). 2020. Mobile cellular subscriptions (per 100 people) - Sub-Saharan Africa. World Telecommunication/ICT Development Report and database. International Telecommunication Union, Geneva, Switzerland.

Johnson, S. 2011. Where good ideas come from: the natural history of innovation. Penguin, New York, New York, USA.

Kasper, C., and M. B. Mulder. 2015. Who helps and why?: cooperative networks in Mpimbwe. Current Anthropology 56 (5):701-732. https://doi.org/10.1086/683024

Kauffman, S. 1996. At home in the universe: the search for the laws of self-organization and complexity. Oxford University Press, Oxford, UK.

Kivikuru, U. 2019. From community to assemblage? ICT provides a site for inclusion and exclusion in the global south. Journal of International Communication 25(1):49-68. https://doi. org/10.1080/13216597.2018.1544163

Kleinbaum, A. M., T. Stuart, and M. Tushman. 2008. Communication (and coordination?) in a modern, complex organization. Harvard Business School, Boston, Massachusetts, USA.

Kobayashi, T., and J. Boase. 2014. Tele-cocooning: mobile texting and social scope. Journal of Computer-Mediated Communication 19(3):681-694. https://doi.org/10.1111/jcc4.12064

Krell, N. T., S. A. Giroux, Z. Guido, C. Hannah, S. E. Lopus, K. K. Caylor, and T. P. Evans. 2021. Smallholder farmers' use of mobile phone services in central Kenya. Climate and Development 13(3):215-227. https://doi.org/10.1080/17565529.2$\underline{020.1748847}$

Lambert, P., and D. Griffiths. 2018. Homophily and endogamy. Pages 13-33 in P. Lambert and D. Griffiths. Social inequalities and occupational stratification. Palgrave Macmillan, London, UK. https://doi.org/10.1057/978-1-137-02253-0 2

Leslie, P., and J. T. McCabe. 2013. Response diversity and resilience in social-ecological systems. Current Anthropology 54 (2):114-143. https://doi.org/10.1086/669563

Lewis, A. L., T. D. Baird, and M. G. Sorice. 2016. Mobile phone use and human-wildlife conflict in northern Tanzania. Environmental Management 58(1):117-129. https://doi.org/10.1007/ s00267-016-0694-2

Ling, R. 2008. New tech, new ties: how mobile communication is reshaping social cohesion. MIT Press Cambridge, Massachusetts, USA. https://doi.org/10.7551/mitpress/7568.001.0001

Mackenzie, C. A., T. D. Baird, and J. Hartter. 2014. Use of single large or several small policies as strategies to manage people-park interactions. Conservation Biology 28(6):1645-1656. https://doi. org/10.1111/cobi.12334

Marler, W. 2018. Mobile phones and inequality: findings, trends, and future directions. New Media \& Society 20(9):3498-3520. https://doi.org/10.1177/1461444818765154

Marmaros, D., and B. Sacerdote. 2006. How do friendships form? Quarterly Journal of Economics 121(1):79-119. https://doi. org/10.1093/qje/121.1.79
McCabe, J., N. Smith, P. Leslie, and A. Telligman. 2014. Livelihood diversification through migration among a pastoral people: contrasting case studies of Maasai in northern Tanzania. Human Organization 73(4):389-400. https://doi.org/10.17730/ humo.73.4.vkr10nhr65g18400

McCabe, J. T., P. W. Leslie, and A. Davis. 2020. The emergence of the village and the transformation of traditional institutions: a case study from northern Tanzania. Human Organization 79 (2):150-160. https://doi.org/10.17730/1938-3525.79.2.150

McCabe, J. T., P. W. Leslie, and L. DeLuca. 2010. Adopting cultivation to remain pastoralists: the diversification of Maasai livelihoods in northern Tanzania. Human Ecology 38(3):321-334. https://doi.org/10.1007/s10745-010-9312-8

McPherson, M., L. Smith-Lovin, and J. M. Cook. 2001. Birds of a feather: homophily in social networks. Annual Review of Sociology 27:415-444. https://doi.org/10.1146/annurev.soc.27.1.415

Miller, B. A. 2000. Geography and social movements: comparing antinuclear activism in the Boston area. University of Minnesota Press, Minneapolis, Minnesota, USA.

Molina, J. L., M. J. Lubbers, H. Valenzuela-García, and S. Gómez-Mestres. 2017. Cooperation and competition in social anthropology. Anthropology Today 33(1):11-14. https://doi. org/10.1111/1467-8322.12323

Monechi, B., Ã. Ruiz-Serrano, F. Tria, and V. Loreto. 2017. Waves of novelties in the expansion into the adjacent possible. PLoS ONE 12(6):e0179303. https://doi.org/10.1371/journal.pone.0179303

Montoya, R. M., and C. A. Insko. 2008. Toward a more complete understanding of the reciprocity of liking effect. European Journal of Social Psychology 38(3):477-498. https://doi. org/10.1002/ejsp.431

Msuya, J., and A. Annake. 2013. The role of mobile phones in facilitating communication among the Maasai pastoralists in Tanzania. Ghana Library Journal 25(1):96-113.

Muto, M., and T. Yamano. 2009. The impact of mobile phone coverage expansion on market participation: panel data evidence from Uganda. World Development 37(12):1887-1896. https://doi. org/10.1016/j.worlddev.2009.05.004

Muyanga, M., and T. Jayne. 2014. Effects of rising rural population density on smallholder agriculture in Kenya. Food Policy 48:98-113. https://doi.org/10.1016/j.foodpol.2014.03.001

Nelson, F., C. Foley, L. Foley, A. Leposo, E. Loure, D. Peterson, M. Peterson, T. Peterson, H. Sachedina, and A. Williams. 2010. Payments for ecosystem services as a framework for communitybased conservation in northern Tanzania. Conservation Biology 24(1):78-85. https://doi.org/10.1111/j.1523-1739.2009.01393.x

Nicholls, W. 2009. Place, networks, space: theorising the geographies of social movements. Transactions of the Institute of British Geographers 34(1):78-93. https://doi.org/10.1111/ j.1475-5661.2009.00331.x

Page, S. E. 2008. The difference: how the power of diversity creates better groups, firms, schools, and societies. Princeton University Press, Princeton, New Jersey, USA. https://doi.org/10.1515/9781400830282 
Pan, W., C. Shen, and B. Feng. 2017. You get what you give: understanding reply reciprocity and social capital in online health support forums. Journal of Health Communication 22(1):45-52. https://doi.org/10.1080/10810730.2016.1250845

Patulny, R. V., and G. Lind Haase Svendsen. 2007. Exploring the social capital grid: bonding, bridging, qualitative, quantitative. International Journal of Sociology and Social Policy 27 (1/2):32-51. https://doi.org/10.1108/01443330710722742

Peet, R., and M. Watts, editors. 2004. Liberation ecologies: environment, development, social movements. Second edition. Routledge, New York, New York, USA.

Phalan, B., M. Onial, A. Balmford, and R. E. Green. 2011. Reconciling food production and biodiversity conservation: land sharing and land sparing compared. Science 333(6047):1289-1291. https://doi.org/10.1126/science.1208742

Qian, Z., and D. T. Lichter. 2007. Social boundaries and marital assimilation: interpreting trends in racial and ethnic intermarriage. American Sociological Review 72(1):68-94. https://doi.org/10.1177/000312240707200104

Quandt, A., J. D. Salerno, J. C. Neff, T. D. Baird, J. E. Herrick, J. T. McCabe, E. Xu, and J. Hartter. 2020. Mobile phone use is associated with higher smallholder agricultural productivity in Tanzania, East Africa. PLoS ONE 15(8):e0237337. https://doi. org/10.1371/journal.pone.0237337

Rivera, M. T., S. B. Soderstrom, and B. Uzzi. 2010. Dynamics of dyads in social networks: assortative, relational, and proximity mechanisms. Annual Review of Sociology 36:91-115. https://doi. org/10.1146/annurev.soc.34.040507.134743

Schreyögg, G., J. Sydow, and P. Holtmann. 2011. How history matters in organisations: the case of path dependence. Management \& Organizational History 6(1):81-100. https://doi. org/10.1177/1744935910387030

Spear, T., and R. Waller, editors. 1993. Being Maasai: ethnicity and identity in East Africa. Ohio University Press, Athens, Ohio, USA.

Summers, K. H., T. D. Baird, E. Woodhouse, M. E. Christie, J. T. McCabe, F. Terta, and N. Peter. 2020. Mobile phones and women's empowerment in Maasai communities: how men shape women's social relations and access to phones. Journal of Rural Studies 77:126-137. https://doi.org/10.1016/j.jrurstud.2020.04.013

Tadesse, G., and G. Bahiigwa. 2015. Mobile phones and farmers' marketing decisions in Ethiopia. World Development 68:296-307. https://doi.org/10.1016/j.worlddev.2014.12.010

Thomas, R. J. 2019. Sources of friendship and structurally induced homophily across the life course. Sociological Perspectives 62(6):822-843. https://doi.org/10.1177/0731121419828399

Van Duijn, M. A., E. P. Zeggelink, M. Huisman, F. N. Stokman, and F. W. Wasseur. 2003. Evolution of sociology freshmen into a friendship network. Journal of Mathematical Sociology 27 (2-3):153-191. https://doi.org/10.1080/00222500305889
Woodhouse, E., and J. T. McCabe. 2018. Well-being and conservation: diversity and change in visions of a good life among the Maasai of northern Tanzania. Ecology and Society 23(1):14. https://doi.org/10.5751/ES-09986-230143

Wyche, S., and C. Steinfield. 2016. Why don't farmers use cell phones to access market prices? Technology affordances and barriers to market information services adoption in rural Kenya. Information Technology for Development 22(2):320-333. https:// doi.org/10.1080/02681102.2015.1048184

Xie, W.-J., M.-X. Li, Z.-Q. Jiang, Q.-Z. Tan, B. Podobnik, W.-X. Zhou, and H. E. Stanley. 2016. Skill complementarity enhances heterophily in collaboration networks. Scientific Reports 6:18727. https://doi.org/10.1038/srep18727 